\title{
ANÁLISE DA RESTRIÇÃO DA OFERTA DE INSUMOS BÁSICOS EM PERÍODOS ECONÔMICOS FAVORÁVEIS DA PERSPECTIVA DE UM FABRICANTE DE
}

\author{
AVIÃO
}

\author{
João Henrique Lopes Guerra \\ jhlg2000@ig.com.br \\ Universidade Federal de Uberlândia - Uberlândia, MG / Brasil
}

http://dx.doi.org/10.1590/1413-2311001201340047

Recebido em 19/02/2014

Aprovado em 03/04/2014

Disponibilizado em 01/08/2014

Avaliado pelo sistema double blind review

Revista Eletrônica de Administração

Editor: Luís Felipe Nascimento

ISSN 1413-2311 (versão on-line)

Editada pela Escola de Administração da Universidade Federal do Rio Grande do Sul.

Periodicidade: Quadrimestral

Sistema requerido: Adobe Acrobat Reader.

\section{RESUMO}

Os fabricantes de avião compartilham fornecedores entre si e com outras indústrias. Nos períodos econômicos favoráveis, a capacidade produtiva da base de fornecimento pode operar próximo do seu limite, gerando disputas (ainda que indiretas) entre os clientes pelos recursos limitados dos fornecedores. A pesquisa teve como objetivo compreender este problema, no caso de insumos básicos, e identificar quais as estratégias que podem ser adotadas para enfrentá-lo. Para tanto, foi realizado um estudo de caso sobre a Embraer. Identificou-se que buscar a garantia do abastecimento por meio de um compromisso formal (o contrato) é necessário, porém não suficiente. Deve-se também, em complemento, buscar um compromisso informal, construído com base no bom relacionamento com os fornecedores. $\mathrm{O}$ compartilhamento da informação sobre a demanda futura é fundamental para que os fornecedores tenham mais segurança nas decisões sobre o aumento de suas taxas de produção e sobre a necessidade de investimentos. A gestão dos riscos associados às restrições de oferta de insumos básicos deve ser realizada por meio de um processo replicado ao longo da cadeia, já que pontos de vulnerabilidade podem existir em diferentes camadas. Os resultados da pesquisa apontam para a necessidade de haver na função compras a preocupação com as questões que envolvem a integração entre os membros da cadeia de suprimentos. Espera-se que esta pesquisa contribua para a compreensão dos desafios enfrentados por uma função cada vez mais estratégica na indústria aeronáutica: a função compras.

Palavras-Chave: Restrição de Recursos; Fabricante de Avião; Indústria Aeronáutica; Estudo de Caso.

\section{ANALYSIS OF SUPPLY RESTRICTION OF BASIC MATERIALS DURING \\ FAVORABLE ECONOMIC PERIODS FROM THE PERSPECTIVE OF AN AIRCRAFT MANUFACTURER}

REAd | Porto Alegre - Edição 78 - N² 2 - maio/agosto 2014 - p. 571-600 
Análise da restrição da oferta de insumos básicos em períodos econômicos favoráveis da perspectiva de um fabricante de avião

\begin{abstract}
The aircraft manufacturers share suppliers among themselves and with other industries. In favorable economic periods, the productive capacity of the supply base can operate close to its limit, generating disputes (although indirect) among customers for limited resources of suppliers. The research aimed to understand this problem in the case of basic materials and identify which strategies can be adopted to face it. To this end, it was conducted a case study on Embraer. It was identified that seek the guarantee of supply through a formal commitment (contract) is necessary, but not sufficient. It must also, in addition, seek an informal commitment, built on good relationships with suppliers. The information sharing about future demand is critical for suppliers to have more security in decisions about increasing their production rates and the need for investment. The risk management associated with supply restrictions of basic inputs should be performed by a process replicated along the chain, as points of vulnerability may exist in different layers. The results point to the concern with the issues surrounding the integration among supply chain members. This research hopes to contribute to the understanding of the challenges faced by an increasingly strategic function in aerospace industry: the purchasing function.
\end{abstract}

Keywords: Restriction of Resources; Aircraft Manufacturer; Aerospace Industry; Case Study.

\title{
ANÁLISIS DE LA RESTRICCIÓN DE LA OFERTA DE SUMINISTROS BÁSICOS EN TIEMPOS ECONÓMICOS FAVORABLES DESDE LA PERSPECTIVA DE UN FABRICANTE DE AVIÓN
}

\begin{abstract}
RESUMEN
Los fabricantes de aviones comparten recursos entre sí y con otras industrias. En períodos económicos favorables, la capacidad productiva de la base de suministro puede operar cerca de su límite, generando disputas (aunque indirectas) entre los clientes por los recursos limitados de los proveedores. La investigación tuvo como objetivo comprender este problema en el caso de los insumos básicos y determinar las estrategias que se pueden adoptar para hacerle frente. Para este fin, se realizó un estudio de caso acerca de Embraer. Se identificó que buscar la seguridad del suministro mediante un compromiso formal (contrato) es necesario, pero no suficiente. También deberá incluir, además, lo compromiso informal, construido sobre las buenas relaciones con los proveedores. El intercambio de información sobre la demanda futura es crucial para que los proveedores tengan más seguridad en las decisiones sobre el aumento de las tasas de producción y la necesidad de inversiones. La gestión de los riesgos asociados a restricciones de suministro de insumos básicos deben ser realizados por un proceso replicado en toda la cadena, ya que puntos de vulnerabilidad pueden existir en diferentes capas de la cadena de suministro. Los resultados apuntan a una preocupación por los temas relacionados con la integración entre los miembros de la cadena de suministro. Se espera que esta investigación contribuye a la comprensión de los desafíos enfrentados por una función cada vez más estratégica en la industria aeronáutica: la función de compras.
\end{abstract}

Palabras Clave: Escasez de Recursos; Fabricante de Avión; Industria Aeronáutica; Estudio de Caso.

REAd | Porto Alegre - Edição 78 - N 2 - maio/agosto 2014 - p. 571-600 


\section{INTRODUÇÃO}

A indústria aeronáutica é caracterizada por uma forte concentração produtiva no que diz respeito ao número de empresas - tanto no caso dos fabricantes de avião, quanto no caso dos seus fornecedores da primeira camada. Assim, há "poucos grandes" fornecedores que são compartilhados pelos seus clientes (LIMA et al., 2005; NIOSI; ZHEGU, 2005). Uma questão importante envolve especificamente os fabricantes de matérias-primas metálicas: eles não fornecem apenas à indústria aeronáutica, mas também aos fabricantes de hardware e a outras indústrias (BASTOS, 2006). Embora as especificações dos materiais utilizados em aplicações aeronáuticas sejam diferenciadas, as matérias-primas básicas são as mesmas usadas em outras indústrias. Na fabricação de um avião, por exemplo, as principais matérias-primas metálicas empregadas são: aço inoxidável, alumínio e titânio. A fabricação de hardwares mecânicos (rebites, porcas, parafusos, etc) e elétricos (fios, cabos, etc) demanda matéria-prima metálica.

As matérias-primas metálicas e os hardwares são fornecidos por empresas tais como a Alcoa, a Rio Tinto Alcan e a Aleris (alumínio), a VSMPO-AVISMA (titânio), a Allfast Fastening Systems (hardware mecânico) e a Tyco Electronics (hardware elétrico). Há, no entanto, outro importante grupo de empresas que fornece estes materiais: os distribuidores, tais como a All Metal Services (matéria-prima) e a Anixter (hardware), que compram de vários fabricantes e os revendem a diferentes clientes. Um cliente tanto pode comprar diretamente do fabricante, quanto do distribuidor.

A indústria aeroespacial representa um dos principais mercados para os produtores de titânio (ILUKA, 2011; TIMET, 2011). Espera-se um aumento na taxa média de crescimento do consumo de titânio na indústria aeronáutica devido à demanda dos novos programas da Boeing e Airbus, por conta da significativa quantidade deste material utilizada em cada avião (CHUNXIANG et al., 2011). As novas gerações de aviões da Boeing e Airbus utilizam de três a quatro vezes mais titânio do que os programas anteriores (HAYES, 2008). Assim, o emprego de titânio em aviões está crescendo (HENRIQUES, 2009). No caso do alumínio, embora a indústria aeronáutica seja um importante cliente de alguns produtos específicos, como chapas e forjados (KING, 2008), há outros importantes consumidores deste tipo de material, como as indústrias de construção civil, automobilística, de embalagens, entre outras (OECD, 2010; BOURIKO, 2012).

Kary (2006) levanta a questão de que restrições de capacidade nos produtores podem afetar o fornecimento de matéria-prima no caso de ocorrerem aumentos simultâneos de demanda em diferentes indústrias. Para a função compras de um fabricante de avião, que 
Análise da restrição da oferta de insumos básicos em períodos econômicos favoráveis da perspectiva de um fabricante de avião

depende deste tipo de material em quantidades volumosas, esta questão é uma fonte de preocupação. Hayes (2008) afirma que a preocupação com o fornecimento de matérias-primas metálicas também existe nos fornecedores dos fabricantes de avião, pois eles têm assumido mais responsabilidades em termos de projeto e fabricação: “com a Boeing e a Airbus confiando de forma crescente aos seus parceiros industriais a produção de estruturas e sistemas, a questão do fornecimento de matérias-primas torna-se mais complexa” (p.5).

\section{O PROBLEMA}

Segundo Randon e Neto (2005), dentre os motivos que levam os fabricantes de aeroestruturas metálicas (montagens estruturais que formam a parte visível do avião, tais como a fuselagem, estabilizadores e asas) a desenvolver novas tecnologias está a preocupação com a falta das principais matérias-primas metálicas. Esta preocupação com a escassez de matérias-primas também existe em outras indústrias (ver PRADO, 2012). No entanto, embora sejam encontrados na literatura muitos artigos que tratam sobre a modelagem ou simulação envolvendo a análise de níveis de estoque e/ou faltas (exemplos: PIERREVAL; BRUNIAUX; CAUX, 2007; MELOUK et al., 2012; SEONG; SUH, 2012), há poucos artigos de periódicos que adotam como tema central a escassez ou falta de insumos básicos da perspectiva de empresas ou indústrias reais, especialmente a aeronáutica - foco deste trabalho. Apenas para ilustrar: uma busca feita no Scopus, em novembro de 2012, usando os termos "shortage", "scarcity" ou "lack" em conjunto com o termo "raw material" e mais os termos "aerospace industry" ou "aircraft manufacturer" (título, palavras-chave e resumo), resultou em apenas dois artigos. Mesmo no caso de buscas mais gerais, os resultados são bastante limitados: uma busca pelo termo "raw material" em conjunto com os termos "Boeing", "Airbus", "Embraer", "Bombardier" ou "aerospace industry" (título, palavras-chave e resumo) resultou em 70 artigos diferentes. Destes, vale destacar apenas os trabalhos de Randon e Neto (2005), Hayes (2008) e Arkhipova (2011). Ainda assim, a contribuição deles ao tema é superficial: Arkhipova (2011), por exemplo, apenas comenta, sem aprofundar, a respeito da dinâmica do mercado consumidor sobre os produtores de titânio.

A busca pela discussão deste tema no contexto de outras indústrias não elimina, mas confirma a lacuna: no caso da indústria automobilística, que compartilha com os fabricantes de avião o consumo e os fornecedores de importantes matérias-primas metálicas, os artigos disponíveis são poucos e, de modo geral, apenas gravitam em torno do tema. Outra característica da escassa literatura refere-se ao fato de que parte dos artigos encontrados que 
citam ou discutem o problema da escassez ou falta de insumos básicos não está ligada a periódicos da área de gestão de operações (alguns exemplos: NADARAJAN; CHANDREN, 2011; VAN HOECKE; LEROY, 2011).

Uma possível explicação para a pouca oferta de artigos que adotam como tema central de estudo a escassez ou falta de insumos básicos da perspectiva de empresas ou indústrias reais talvez seja o fato deste problema envolver estratégias e processos internos das empresas, que elas costumam não estar muito dispostas a divulgar. Porém, não restringindo a busca especificamente aos artigos de periódico, é possível encontrar na literatura alguns casos que permitem compreender com maior profundidade e clareza o risco citado anteriormente por Kary (2006). Bilczo et al. (2003), Budiman (2004), Vacha Junior (2007) e Harper (2008) estudaram o caso das matérias-primas metálicas. Vacha Junior (2007) estudou o caso do titânio, enquanto que Harper (2008) estudou o caso do alumínio e do titânio. Bilczo et al. (2003) estudaram o caso de uma liga metálica com larga utilização na indústria aeronáutica (mas sem especificar qual). Budiman (2004) faz uma análise deste último trabalho. O restante deste item foi baseado nestes quatro trabalhos, conjuntamente (a não ser quando explicitado).

A flutuação da demanda por novos aviões causa flutuação na demanda destes materiais. A flutuação pode ser tão severa que, em períodos de baixa demanda, há produtores que têm que deixar o mercado. Os que permanecem ajustam suas capacidades lentamente durante os períodos de crescimento da demanda. Isto ocorre porque os ciclos que o mercado sofreu no passado tornaram os produtores cautelosos: eles tomam uma decisão de acréscimo da capacidade apenas quando têm segurança de que o maior nível de demanda é sustentável ou se manterá por um tempo suficientemente longo para cobrir os investimentos. Este comportamento faz com que a indústria produtora de matérias-primas siga "em atraso" os ciclos da indústria de seus clientes. A saída de produtores do mercado e o acréscimo lento da capacidade pelos que permanecem nele afetam a disponibilidade de capacidade. Como resultado, o mercado destes materiais tem sido cíclico por natureza: durante os períodos de alta demanda os produtores operam próximo da sua capacidade máxima, enquanto que em períodos de demanda reduzida eles se esforçam para se manterem lucrativos. Assim, existe uma flutuação entre sub e sobrecapacidade, entre falta e excesso de material.

Harper (2008) defende que a oferta de matéria-prima não é influenciada apenas pelo fator econômico relacionado à ciclicidade da indústria aeronáutica, mas também por fatores técnicos: o processo produtivo do titânio é caro, demorado e em lote. Estas características tornam difícil a alteração dos volumes de produção rapidamente. Já no caso do alumínio, 
Análise da restrição da oferta de insumos básicos em períodos econômicos favoráveis da perspectiva de um fabricante de avião

como o seu processo produtivo demanda muita energia, o preço crescente desta induziu muitos produtores a manterem sua capacidade ociosa, segundo o autor.

Quando a economia está em expansão, a demanda de todas as indústrias pressiona os produtores, gerando aumento no preço e no lead-time. Por exemplo: entre 1993 e 1997, o preço da liga estudada por Bilczo et al. (2003) aumentou cerca de 100\%, enquanto que o seu lead-time aumentou $800 \%$. Isto provocou a paralisação de linhas de montagem de 737 e 747 na Boeing e forçou a empresa a gastos de hora-extra e multas às companhias aéreas devido ao atraso nas entregas. Em outro exemplo, Vacha Junior (2007) cita que no final de 2003 o leadtime do lingote de titânio era de onze semanas, mas chegou em sessenta semanas no primeiro semestre de 2006. Chunxiang et al. (2011, p.1685) relatam que "durante 2003-2006, o preço do titânio aumentou a uma taxa sem precedentes".

Em um mercado restrito, o crescimento dos preços gera outro interessante efeito, identificado por Harper (2008). Conforme o preço aumenta, aumenta também a expectativa sobre os preços futuros. Isto pode levar alguns clientes a comprarem além da sua necessidade, antes que os preços aumentem ainda mais. Esta estratégia alimenta um looping danoso: estas compras, que visam atender uma demanda "artificialmente inflacionada", restringem o fornecimento, o que, por sua vez, favorece o aumento do preço (cabe contextualizar que este efeito, relacionado ao crescimento da variabilidade da demanda conforme ela se move à montante da cadeia de suprimentos, foi originalmente estudado por FORRESTER, 1958, 1961; a dinâmica que este efeito causa nas cadeias de suprimentos ainda é um tema central em gestão de operações, conforme destacado por KOUVELIS; CHAMBERS; WANG, 2006). Assim, trata-se do típico comportamento em que a busca pelo ótimo individual (de uma única empresa) pode levar a uma situação ruim quando se considera a indústria como um todo.

Considerando esta discussão e sua relevância para a indústria aeronáutica, buscou-se nesta pesquisa responder às seguintes questões: de que forma o problema da restrição da oferta de insumos básicos (tais como matérias-primas e hardwares) afeta um fabricante de avião? Quais estratégias podem ser adotadas para enfrentá-lo?

\section{OBJETIVO E MÉTODO}

A indústria aeronáutica é uma das mais importantes do mundo, sendo "estratégica para a afirmação tecnológica, econômica e militar” de um país (BEDAQUE JUNIOR, 2006, p.100) e um "núcleo dinamizador da economia" (CHAGAS JUNIOR, 2005, p.2). Ela é caracterizada por ter grandes barreiras de entrada - tanto que, atualmente, o grupo dos principais fabricantes 
de aviões comerciais e executivos é composto por apenas quatro empresas: a americana Boeing e a europeia Airbus, no caso dos grandes aviões, e a canadense Bombardier e a brasileira Embraer, no caso dos aviões médios.

Para Barbieri (2008, p.19), “a indústria aeronáutica brasileira se consolidou, nas últimas décadas, como uma das mais importantes do mundo". Este fato, em muito, está relacionado à Embraer: para um país com poucas empresas intensivas em tecnologia, ela se destaca por ter crescido em um dos mercados mais sofisticados do mundo (MARTINEZ, 2007). "A indústria aeronáutica em geral e, a Embraer em particular", podem ser consideradas como fundamentais "para o desenvolvimento econômico, tecnológico e geopolítico do Brasil" (BARBIERI, 2008, p.5).

Devido à importância deste setor e da preocupação dos fabricantes de avião com o abastecimento de insumos básicos, considerando que este tipo de empresa demanda grandes volumes destes materiais, foi realizado um estudo de caso na Embraer visando responder as questões anteriores. O foco do estudo de caso foram os programas civis da Embraer (aviação comercial e executiva), já que os militares possuem uma dinâmica toda particular, além de terem atualmente uma importância relativa menor quando comparados aos civis. Quanto ao tipo, esta pesquisa pode ser classificada como qualitativa, pois seu objetivo foi compreender um fenômeno, ao invés de mensurá-lo. Quanto à escolha da estratégia de pesquisa, Miguel (2007) explica que ela deve atender à questão de pesquisa de modo a proporcionar um caminho para respondê-la. Esta relação entre a questão de pesquisa e a estratégia de pesquisa também aparece em Yin (2005), que defende que a forma da questão fornece um indício importante para a escolha da estratégia. Baseado em Yin (2005), as características do fenômeno e seu ambiente sugeriram a escolha do estudo de caso como estratégia de pesquisa. Quanto à unidade de análise, foi selecionada a função compras de um fabricante de avião (no caso, da Embraer), por estar diretamente envolvida com o problema estudado. Como foi usada apenas uma unidade de análise, o caso selecionado pode ser classificado, segundo Yin (2005), como holístico. Portanto, a estratégia adotada nesta pesquisa foi a do estudo de caso único. Como esta pesquisa mostra um instantâneo da situação do fenômeno (ou seja, o fenômeno foi pesquisado em um momento preciso e não ao longo do tempo), ela pode ser classificada como sendo de corte transversal.

Nesta pesquisa, as seguintes fontes de dados foram utilizadas: a literatura disponível que trata direta ou indiretamente do tema; informações públicas disponibilizadas por empresas 
Análise da restrição da oferta de insumos básicos em períodos econômicos favoráveis da perspectiva de um fabricante de avião

(documentos, informações à imprensa, etc); reportagens divulgadas na imprensa; entrevistas com informantes-chave.

Devido às características da indústria aeronáutica (um setor de alta tecnologia cujas empresas, especialmente os fabricantes de avião, têm particular cuidado com as informações que envolvem seus processos internos), foram tomadas duas decisões com o objetivo de favorecer o rigor da pesquisa. Primeira: optou-se por manter em sigilo a identidade dos entrevistados. Segunda: por sugestão de Miguel (2007), preferiu-se registrar durante as entrevistas os dados manualmente, já que "a gravação pode ser intrusiva no sentido de inibir o entrevistado" (p.223). Pelos resultados alcançados nas entrevistas, em termos de qualidade e aprofundamento das informações, bem como pelas opiniões expressas pelos entrevistados a respeito destas duas decisões, o autor recomenda que elas sejam adotadas em outras pesquisas envolvendo os fabricantes de avião.

Miguel (2007) também sugere que sejam realizadas entrevistas com funcionários de diferentes níveis hierárquicos. Esta sugestão foi particularmente importante nesta pesquisa, porque permitiu analisar o problema de diferentes perspectivas, considerando que cargos diferentes podem ter visões diferentes sobre o mesmo problema, já que as responsabilidades, o tipo e o nível das decisões e ações mudam. Ao todo foram realizadas nove entrevistas face a face, individuais e semiestruturadas. As entrevistas ocorreram em dias diferentes e tiveram uma duração média de duas horas e dezessete minutos. Foram entrevistados três gerentes (responsáveis pela compra de diferentes tipos de matéria-prima e outros insumos utilizados na fabricação dos aviões), quatro supervisores (cada um, líder de um grupo de compradores) e dois compradores. Todas as pessoas entrevistadas estão ligadas à unidade de análise escolhida na pesquisa: a função "compras de um fabricante de avião". Os entrevistados apresentam uma experiência média de aproximadamente oito anos na função compras da Embraer. Optou-se por entrevistar um número maior de pessoas ligadas a cargos de chefia por terem uma visão mais estratégica do problema estudado. O número de entrevistas foi definido com base na “saturação teórica” (EISENHARDT, 1989).

Com o objetivo de favorecer a triangulação de dados (ver YIN, 2005), optou-se por realizar entrevistas com: funcionários da Embraer que atualmente trabalham na função compras; funcionários da Embraer que trabalharam na função compras, mas que atualmente estão em outra função da empresa; pessoas que trabalharam na função compras da Embraer, mas que já deixaram a empresa (são ex-funcionários). Todos os nove entrevistados pertencem a algum destes três grupos. Apesar de não terem sido identificadas diferenças significativas 
nas informações coletadas destes três grupos de entrevistados, esta decisão foi válida porque permitiu comparar a visão que diferentes pessoas têm sobre um objeto, mas que diferem entre si pelo compromisso que atualmente possuem em relação a este objeto. A questão que motivou esta decisão foi a seguinte: existe algum risco dos funcionários atuais da função compras da empresa agirem durante as entrevistas com base em um discurso tendencioso ou "pronto" (combinado)? É importante destacar que, visando garantir que o contexto analisado pelos entrevistados fosse o mesmo, tomou-se o cuidado de escolher pessoas que não deixaram a Embraer ou a função compras da empresa há mais de dois anos.

Considerando a escolha do estudo de caso como método de pesquisa, a análise dos dados foi baseada em Yin (2005). Uma primeira análise da literatura permitiu identificar os tópicos que, da perspectiva desta fonte de dados, deveriam ser compreendidos para que as questões de pesquisa pudessem ser respondidas. Os tópicos identificados foram os seguintes: a oferta restrita de insumos básicos em períodos econômicos favoráveis; a competição entre indústrias por insumos básicos (compartilhamento de fornecedores); o poder de barganha entre cliente-fornecedor; a possível priorização, por parte de produtores e distribuidores de insumos básicos, dos clientes mais importantes; a importância relativa da empresa analisada na pesquisa comparativamente a outros clientes; os aspectos formais e informais associados ao relacionamento cliente-fornecedor; o problema da falta de materiais enfrentado pela função “compras de um fabricante de avião": impactos, e possíveis estratégias para enfrentá-lo. A identificação destes tópicos realimentou a busca por novas fontes de dados, bem como orientou a preparação do questionário das entrevistas: as questões foram definidas de tal forma a cobrir estes diferentes tópicos sugeridos pela literatura.

Uma análise detalhada das fontes de dados coletadas (artigos, teses, entrevistas, etc) permitiu selecionar, em cada fonte, as partes (um trecho de artigo, uma resposta a uma questão do questionário, etc) relacionadas aos tópicos anteriores. Buscou-se, então, interpretar estas partes selecionadas, ou seja, compreender o que o autor ou o entrevistado quis dizer, atribuindo um significado à análise. As diversas partes selecionadas e interpretadas foram depois confrontadas entre si, dentro do seu tópico específico, visando identificar quais eram similares entre si (sugeriam uma mesma ideia, eram convergentes, complementares, tinham o mesmo padrão). Cada conjunto de partes selecionadas identificadas como similares formou um subtópico dentro de um dos tópicos anteriores. Cada subtópico foi criado por meio do processo de triangulação de dados, ou seja, da consideração de um conjunto de partes selecionadas convergentes entre si, obtidas das diferentes fontes de dados. Posteriormente, foi 
Análise da restrição da oferta de insumos básicos em períodos econômicos favoráveis da perspectiva de um fabricante de avião

realizada uma interpretação geral sobre cada subtópico. As interpretações obtidas dos diversos subtópicos foram confrontadas entre si, permitindo identificar linhas divergentes ou conflitantes entre os subtópicos. A compreensão de cada tópico ocorreu por meio de uma explanação (no caso, textual) que levou em consideração as interpretações relacionadas aos seus diversos subtópicos, adequando-se o máximo possível (mas não necessariamente perfeitamente) a elas. A explanação relacionada a cada tópico foi, portanto, fruto de um processo de conciliação das interpretações obtidas dos seus diferentes subtópicos. Finalmente, analisou-se criticamente se as explanações realmente permitiam compreender os tópicos.

No caso das entrevistas, é importante destacar que foi solicitada a cada um dos entrevistados a checagem das interpretações realizadas pelo autor com base nos dados coletados nas entrevistas. Esta ação foi combinada com os entrevistados ao final da entrevista quando, então, foram definidos uma data para o envio das interpretações e um prazo para que eles pudessem analisá-las. Além disso, por sugestão de Yin (2005) e Miguel (2007), foi usado um protocolo para orientar a coleta de dados por meio das entrevistas. Yin (2005) explica que o protocolo engloba o instrumento de coleta de dados (o questionário) e também contém as regras e os procedimentos a serem seguidos no emprego do instrumento. O protocolo adotado foi o proposto por Guerra (2010), adequado ao tipo de pesquisa realizado. Também cabe destacar que foi realizada uma entrevista-piloto com um funcionário da função compras da Embraer com experiência em pesquisa científica. Esta entrevista teve como objetivo receber uma análise crítica de um indivíduo “... com características similares aos da população a ser investigada" (MORON, 1998, p.70) sobre o protocolo do estudo de caso, o comportamento do pesquisador durante a entrevista e o próprio questionário elaborado.

\section{A FUNÇÃO COMPRAS}

A função compras é responsável por obter os materiais e serviços que uma empresa necessita para produzir e fornecer os seus produtos (JOYCE, 2006). Atualmente, diferentes empresas e indústrias apresentam características ou seguem tendências que colocam esta função em evidência (ver: FERREIRA, 2010; JOHNSON; LEENDERS; FLYNN, 2010). Uma influente teoria do planejamento estratégico também tem contribuído para a importância da função compras.

Para Prahalad e Hamel (1990), no curto prazo a competitividade de uma empresa depende de fatores como preço e o desempenho de seus produtos. Porém, no longo prazo, ela depende da capacidade de formar competências essenciais, a um custo menor e com uma 
velocidade maior do que seus concorrentes. Assim, no futuro os gestores serão julgados mais pela capacidade de identificar, cultivar e explorar as competências essenciais da organização. Os autores definem uma competência essencial como o aprendizado coletivo da organização, um conjunto único de capacidades que permite à empresa criar grandes produtos. Uma competência essencial fornece uma contribuição significativa para os benefícios que os clientes percebem no produto final da empresa, é de difícil imitação e provê à empresa acesso potencial a diferentes mercados. Estas ideias estão associadas à Visão Baseada em Recurso (VBR). À luz da VBR, considera-se que uma empresa deve manter internamente apenas as operações ou itens relacionados às competências essenciais, sendo os outros transferidos a empresas que, por serem especializadas, podem produzi-los de uma maneira mais eficiente.

Influenciadas ou não por esta teoria, o fato é que muitas empresas atualmente estão utilizando uma parte considerável de suas receitas na obtenção de bens e serviços de fornecedores. Fitzgerald (2002) cita trabalhos que mostram que algumas empresas de manufatura investem mais de $70 \%$ de suas receitas em materiais e serviços obtidos de fonte externa, enquanto que Van Weele (2010) mostra exemplos em que esta porcentagem chega a 80\%. No caso de empresas da indústria aeronáutica, Texier (2008), Clarke (2010) e EADS (2010) apresentam porcentagens que variam de 70 a 90\%. Na Embraer, este valor chega a "mais de 80\%" (EMBRAER, 2007, p.120). Em indústrias tais como a automobilística e a aeronáutica os fornecedores têm assumido mais responsabilidades e intensificado sua participação no processo de desenvolvimento de produtos de seus clientes, o que pode estar influenciando estas altas porcentagens. Esta discussão, na realidade, envolve os modelos de negócio adotados nestas indústrias: o modelo dos modulistas/sistemistas, no caso da primeira (ver, por exemplo, GRAZIADIO, 2004), e o modelo de integração de sistemas dos fabricantes de avião, no caso da segunda (ver, por exemplo, GUERRA, 2011).

Na medida em que uma empresa obtém de outras empresas muitos dos recursos de que necessita, ela se torna dependente de sua base de fornecimento (CARTER; MONCZKA; MOSCONI, 2005). Neste contexto, o papel da função compras ganha destacada relevância, já que a gestão desta base passa a ser uma questão crítica (estratégica), com influência direta na competitividade da empresa. A maior importância estratégica da função compras atualmente tem sido citada por diferentes autores na literatura. Fitzgerald (2002) defende que a posição ocupada atualmente pela função compras é privilegiada em relação à de outras funções quanto à influência na lucratividade das empresas. Carter, Monczka e Mosconi (2005) e Van Weele (2010) também ressaltam a maior representatividade e importância estratégica desta função. 
Análise da restrição da oferta de insumos básicos em períodos econômicos favoráveis da perspectiva de um fabricante de avião

No caso da Embraer, esta importância estratégica é facilmente observada. Dorna et al. (2004, p.3641) citam que "as áreas inerentes ao processo de gestão da cadeia de suprimentos da empresa passaram a ser forte e estrategicamente privilegiadas, assumindo [...] um papel central no padrão de competitividade da Embraer em sua fase pós-privatização”. Nesta empresa, há não muitos anos atrás o atendimento da produção era realizado por uma única "gerência de suprimentos", hoje transformada em uma diretoria com nome bastante sugestivo: "gestão da cadeia de suprimentos". A gerência original, que tinha um escopo relativamente amplo, multiplicou-se e organizou-se em várias gerências com focos específicos em função do ciclo de vida do produto, do segmento de mercado e do tipo de material. Esta diretoria ganhou evidência e força na empresa nos últimos anos (informações obtidas na pesquisa de campo).

\section{A LIGAÇÃO DE “NÃO MEMBRO” EM UMA CADEIA DE SUPRIMENTOS}

Lambert, Cooper e Pagh (1998) sugerem a consideração de alguns aspectos estruturais relacionados a uma cadeia de suprimentos. Dentre os aspectos discutidos, está o tipo de ligação que uma empresa pode ter com outros membros de sua cadeia. Para esta pesquisa, é particularmente importante a chamada ligação de "não membro", ilustrada na Figura 1.

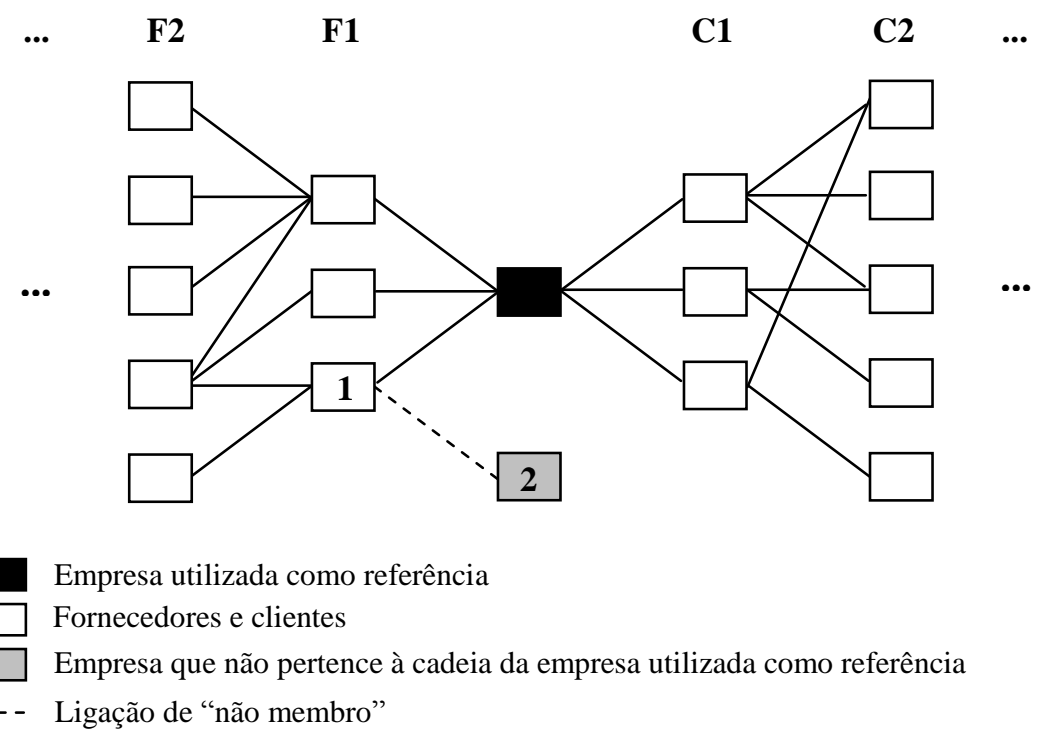

Figura 1 - Representação da ligação de "não membro" Fonte: Lambert, Cooper e Pagh (1998, p.7)

Da perspectiva da empresa utilizada como referência (preenchida com a cor preta), a ligação entre a empresa 1 e a empresa 2 é uma ligação de "não membro", que é definida como aquela existente entre um membro da sua cadeia e o membro de outra cadeia. Sob a ótica desta empresa usada como referência, embora esta ligação não pertença a sua cadeia, ela pode 
influenciar seu desempenho e o da sua cadeia. Exemplo: a empresa pode ter um determinado fornecedor que fornece também a um de seus concorrentes. Se o fornecedor tiver escassez de recursos e o concorrente for um cliente importante, esta ligação pode ser um ponto vulnerável para a empresa.

\section{RESULTADOS: ANÁLISE DO PROBLEMA DA PERSPECTIVA DA EMBRAER}

A seguir são discutidos os resultados da pesquisa: o problema da restrição da oferta de insumos básicos da perspectiva de um fabricante de avião (no caso, a Embraer) e a análise das estratégias que podem ser adotadas para enfrentá-lo.

\subsection{Disputas entre os clientes pelos recursos limitados dos fornecedores}

O ponto de vulnerabilidade associado à ligação de "não membro" descrita no item 4 é claramente observado na indústria aeronáutica, conforme ficou evidente nas entrevistas. Por causa da concentração de fornecedores e do compartilhamento de fornecedores entre os clientes, nos períodos econômicos favoráveis em que ocorre um crescimento do transporte aéreo e, consequentemente, da demanda por novos aviões, a capacidade produtiva da base de fornecimento pode operar próximo do seu limite. Nestas circunstâncias, pode haver uma disputa entre os clientes, ainda que indireta, por uma oferta restrita. Os relatos dos entrevistados mostraram que esta restrição da oferta pode afetar diferentes sistemas que compõem um avião. Especificamente no caso de matérias-primas e hardwares as disputas se ampliam, pois envolvem clientes que não pertencem à indústria aeronáutica, além dos próprios distribuidores. Como os grandes distribuidores compram grandes volumes (pois atendem a clientes em diferentes indústrias), eles possuem um considerável poder de barganha sobre os fornecedores. Nesta discussão, um entrevistado chamou a atenção para a presença de outro importante agente: a área de defesa americana, que representa um mercado "forte e relativamente seguro" para os fornecedores e distribuidores e que exige "contratos rígidos".

Durante a pesquisa de campo, ficou clara a preocupação da função compras da Embraer com o abastecimento de matérias-primas e hardwares. Porém, evidentemente, esta preocupação é maior nas situações discutidas pelos autores citados no item 1: quando, nos períodos econômicos favoráveis, podem ocorrer faltas generalizadas de materiais devido ao crescimento da demanda. De acordo com os entrevistados, há alguns anos houve uma grave crise de falta de matéria-prima (alumínio e titânio) e prendedores (que é como os hardwares mecânicos usados para prender ou fixar objetos são conhecidos; segundo TEXIER, 2008, 
Análise da restrição da oferta de insumos básicos em períodos econômicos favoráveis da perspectiva de um fabricante de avião

como os prendedores são feitos principalmente de alumínio, a sua disponibilidade depende da oferta e do preço deste material). Nesta ocasião, os principais elementos descritos pelos autores citados estavam presentes: "houve um aquecimento da demanda que aconteceu em vários lugares ao mesmo tempo e os fornecedores não estavam preparados para atender"; "tivemos que aceitar condições de lead-time e preço dos fornecedores". Para alguns dos entrevistados, a demanda gerada pelos novos programas da Airbus (A380) e da Boeing (787 Dreamliner) contribuiu para a crise. O problema com os prendedores, que ocorreu em 2007, é citado em Johnsson e Greising (2007) e em The Economist (2007). Por causa da preocupação com o abastecimento relacionado a este tipo de material, não é surpresa encontrar os fabricantes de avião celebrando por meio de notas oficiais o fechamento de contratos importantes (ver as informações à imprensa divulgadas pelos fabricantes de avião em seus sites nas seguintes datas: 19/07/2006 e 05/12/2006, no caso da Embraer; 11/08/2006, no caso da Boeing; 20/04/2009, no caso da Airbus; ver também HAYES, 2008).

A flutuação da demanda que é refletida ao longo da cadeia de suprimentos pode ser representada por uma declaração de um entrevistado: “em 2007, a gente precisava de material e não conseguia obter”. Já em 2010, período em que a Embraer ainda sofria os efeitos da crise financeira, ele afirmou que a empresa teve sobra (excesso) de material. Assim, "o 'pêndulo ficou' nas duas extremidades".

Durante as entrevistas, as discussões contemplaram uma questão relevante: será que em períodos de restrição da oferta os fornecedores dão preferência a determinados clientes? Se sim, o fato da Embraer ser menos importante do que outros clientes (como a Boeing e a Airbus) influência esta priorização ou preferência? As palavras de um entrevistado resumem o que foi ouvido nas entrevistas: “o fornecedor sempre vai querer atender todo mundo. Quando há o suficiente, não precisa haver priorização A priorização ocorre em função de escassez de recurso ou de restrição de capacidade". Nestas circunstâncias, uma escolha sobre quem será atendido pode ser inevitável. Portanto, a priorização é algo compreensível, que ocorre mesmo dentro de uma empresa: os produtos ou programas mais importantes tendem a receber os melhores recursos. Se a priorização pode ser inevitável em determinadas situações, resta saber se os critérios adotados pelos fornecedores colocam a Embraer em segundo plano. Os entrevistados mostraram duas opiniões bem evidentes. Em termos gerais, eles acreditam que os critérios de priorização seriam: "faturamento" e "pressão". Ou seja: o cliente que faz mais pressão nos fornecedores ou que garante a eles a maior receita seria priorizado. Assim, a primeira opinião foi: a Embraer fica em segundo plano em relação aos clientes mais 
importantes, como a Boeing e a Airbus. No entanto, nem uma única evidência convincente e confiável que comprovasse isto foi fornecida durante as entrevistas. As opiniões foram expressas por meio de um misto de "eu acho, mas não tenho certeza" e exemplos cujas motivações poderiam envolver as mais diversas causas - e não necessariamente ou unicamente a "discriminação" da Embraer em relação aos clientes "maiores". A segunda opinião que ficou evidente de certa forma compensa (pelo menos em parte) a anterior: há um consenso entre os entrevistados de que a Embraer, como cliente, está se tornando cada vez mais importante e os fornecedores têm cada vez mais consciência disto. Um deles citou: “analisar a importância da Embraer apenas em termos de faturamento não é o melhor indicador. A empresa é a que mais cresce em termos de aviação executiva e é líder em um nicho específico (a aviação comercial regional)". Portanto, não foi possível comprovar nesta pesquisa se os fornecedores colocam (ou não) a Embraer em segundo plano em determinadas situações e em relação a determinados clientes.

\subsection{Estratégias para enfrentar o problema}

Partindo-se da compreensão do caso da Embraer, são discutidas a seguir as estratégias que poderiam ser utilizadas com o propósito de minimizar o risco de um fabricante de avião ter problemas de abastecimento de insumos básicos por conta de restrições de capacidade dos fornecedores, especialmente nos períodos econômicos mais favoráveis em que empresas de diferentes indústrias buscam garantir a sua "fatia do bolo".

5.2.1 Compromisso formal e práticas que visam melhorar o relacionamento com os fornecedores

O relacionamento entre as empresas demanda tempo até crescer e se desenvolver. Desta forma, ele é tal qual o relacionamento entre as pessoas. Além disso, ele envolve tanto aspectos mais objetivos, como os contratos, quanto aspectos mais subjetivos, como é o caso do nível de confiança entre as empresas. Nesta linha, Sucupira (2007, p.14) defende que o bom relacionamento não deve ficar apenas na esfera informal, no "aspecto comportamental de confiança", mas necessita da "formalização de regras de negócio".

Com base no caso da Embraer foi possível identificar a importância da adoção de relações formais em conjunto com práticas que favorecem o (bom) relacionamento com os fornecedores. O contrato de fornecimento representa o mecanismo formal da empresa para 
Análise da restrição da oferta de insumos básicos em períodos econômicos favoráveis da perspectiva de um fabricante de avião

garantir o seu abastecimento de materiais: "quase todos os nossos custos de materiais são cobertos por contratos de longo prazo com nossos fornecedores. Os preços [...] geralmente são corrigidos com base em uma fórmula de reajuste que reflete, em parte, a inflação nos Estados Unidos da América" (EMBRAER, 2007, p.72). De acordo com os entrevistados, a empresa tem evoluído no processo de negociação e gestão dos seus contratos. A regra geral adotada atualmente é ter contrato formal com todos os fornecedores. Os entrevistados explicaram que os contratos de fornecimento de todos os materiais, excetuando-se hardwares e matériasprimas, são específicos a cada programa e cobrem todo o ciclo de vida do produto. No caso de hardwares e matérias-primas, eles cobrem alguns anos e atendem a todos os programas, já que os materiais são comuns (há alguns detalhes sobre os contratos de fornecimento da Embraer em: SANTIAGO, 2002; LIMA et al., 2005).

Segundo Dwyer, Schurr e Oh (1987), é impossível cobrir em um contrato formal todas as possíveis contingências que podem surgir a partir do momento em que duas empresas decidem realizar negócios. Daí a importância do papel complementar que a confiança pode desempenhar: ela permite "substituir controles formais e contratos" (ALVES FILHO et al., 2004, p.284). De fato, as entrevistas mostraram que buscar o compromisso formal (legal) de fornecimento através do contrato não basta. Ele é essencial, mas não suficiente. Devido às restrições de oferta que afetam alguns materiais também é importante buscar o compromisso informal, que é fomentado pelos laços do bom relacionamento. Durante um período de dificuldade em que um fornecedor não conseguir honrar os compromissos formais com todos os seus clientes, será este outro tipo de compromisso que irá determinar quem será atendido (ou receberá o melhor atendimento). De fato, há situações que os contratos não cobrem e, mesmo naquelas cobertas, o bom relacionamento e a confiança podem ser mais eficazes: "no contrato constam as situações extremas que não foram resolvidas na boa vontade, na confiança mútua"; "existem situações em que você precisa dizer ao fornecedor: "esquece o contrato, eu preciso da sua ajuda". Esta é, de modo geral, a opinião dos entrevistados. Eles acreditam que: "é possível conseguir prioridade e resposta dos fornecedores com base em um bom relacionamento construído desde o nível operacional”; “é possível fazer contratos bem mais elaborados: se acontecer aquilo a situação é essa e por aí vai. Porém, não é uma penalidade alta que vai motivar o fornecedor a diminuir o risco que você tem: é investindo no relacionamento que você consegue alguma coisa"; "o mais importante é o relacionamento entre as empresas". 
É neste contexto que os entrevistados defendem a adoção de práticas que visam melhorar o relacionamento com os fornecedores. Duas que merecem destaque na Embraer são as seguintes (ver mais detalhes sobre estas práticas em: FERNANDEZ, 2004; EMBRAER, 2011):

- Embraer Suppliers Conference (ESC): é um evento que reúne várias funções da empresa (inteligência de mercado, compras, desenvolvimento de produto, produção, etc), os fornecedores e até alguns clientes. No evento são compartilhadas informações estratégicas sobre mercados, perspectivas futuras, novos programas, etc, além de ocorrer a premiação dos melhores fornecedores (Embraer Suppliers Award).

- Supply Chain Alignment (SCA): evento mais direcionado ao contexto da função compras, conta ainda com a participação de algumas outras áreas da empresa e os principais fornecedores. Nele são discutidos vários assuntos: o plano de produção (evolução, entregas, etc), indicadores relacionados aos fornecedores (por exemplo: ordens de compra em atraso), níveis de estoque (incluindo os materiais em reparo e quarentena), novos modelos de planejamento, etc.

\subsubsection{Compartilhamento de informação}

Conforme Power (2005, p.260) afirma, a integração da cadeia de suprimentos é uma necessidade "inerentemente estratégica e uma fonte potencial de vantagem competitiva". A base da integração da cadeia é o compartilhamento de informação (LEE, 2000). De fato, o fluxo de informações é tão importante quanto o fluxo de produtos (STEVENSON; SPRING, 2007).

A função compras da Embraer envia periodicamente aos fornecedores a demanda futura dos materiais (que cobre alguns anos), chamada de forecast (previsão). Ela é obtida por meio da tradução do plano de produção da empresa (programa de montagem e entrega de aviões) em termos de necessidades de materiais ao longo do tempo. No caso dos materiais mais críticos, tais como matérias-primas metálicas, a discussão feita no item 1 revelou que tão importante quanto o compartilhamento desta informação é a garantia da sua acuracidade. Considerando a dificuldade que os produtores de matérias-primas têm para variar suas taxas de produção, o fabricante de avião (e, de modo geral, toda a cadeia de suprimentos) deve assumir o compromisso de fornecer a informação mais confiável possível sobre a demanda futura. Como a demanda pode variar por questões que não estão sob o seu controle, o 
Análise da restrição da oferta de insumos básicos em períodos econômicos favoráveis da perspectiva de um fabricante de avião

fabricante de avião também deve ter o compromisso de atualizá-la junto aos produtores tão logo e sempre que ela sofrer mudanças. Buscar melhorar a qualidade desta informação é fundamental para que os produtores tenham mais segurança em suas análises e decisões envolvendo as alterações das taxas de produção e a necessidade de investimentos em capacidade. Nesta discussão, cabe citar Harper (2008). Este autor comenta o caso da Boeing que contratou uma empresa para comprar matéria-prima (titânio, alumínio e fibra de carbono) de forma centralizada para a sua cadeia: "os contratos estipulados pela Boeing geralmente desencorajam compras spot [compra pontual que visa suprir uma necessidade imediata ou específica] [...]. Isto permite que a Boeing alcance descontos de volume através da compra centralizada e [...] assegura que a indústria não entre em loops destrutivos [ver o item 1] que poderiam prolongar as faltas" (p.48).

A função compras da Embraer adota estoque de segurança para muitos dos itens comprados. De fato, esta é uma prática que, por causa do receio que as empresas da indústria aeronáutica têm de não cumprir as datas combinadas com seus clientes, é comum nesta indústria (ver, por exemplo, VACHA JUNIOR, 2007). Sobre esta estratégia, é importante fazer duas observações. Quando uma empresa decide formar este tipo de estoque, isto é traduzido do lado do fornecedor como um aumento da demanda. Visando evitar que esta decisão contribua para o "looping danoso" descrito no item 1, é importante que ela seja combinada previamente com o fornecedor. Na prática, esta ação favorece a qualidade da informação que é compartilhada: o fornecedor saberá a razão do acréscimo da demanda e que ele é pontual. A segunda observação vem de Harper (2008): este autor lembra que a formação de estoque de segurança para materiais que já possuem problemas de abastecimento pode acabar gerando mais pressão nos fornecedores. Portanto, implementar esta estratégia demanda cuidado.

5.2.3 Integração do processo de gestão de risco em cadeias de suprimentos

"O risco é um aspecto sempre presente da vida organizacional" (KHAN; BURNES, 2007, p.211). O conceito de risco tem um escopo relativamente amplo. Ele tem sido objeto de extensiva análise em diferentes contextos, sob diferentes perspectivas (CUCCHIELLA; GASTALDI, 2006). Em algumas áreas, como a financeira, o tema é bastante explorado (KHAN; BURNES, 2007). No contexto das cadeias de suprimentos, a gestão de risco vem ganhando muita atenção, inclusive com edições especiais nas principais revistas acadêmicas 
(ver OLSON; WU, 2010). De acordo com Pimpão e Ferreira (2010, p.2), "a importância que a gestão de risco em cadeias de suprimentos tem ganhado pode ser observada através do número crescente de estudos sobre o tema e é um sinal do seu impacto no desempenho das organizações". O fato é que "a natureza e a grande complexidade das cadeias de suprimentos as tornam particularmente vulneráveis a riscos" (WATERS, 2007, p.11). Assim, as empresas ficam expostas a uma enorme gama de eventos incertos que podem afetar suas operações inesperadamente.

A gestão de risco, em essência, é uma abordagem proativa para gerenciar os riscos antecipadamente, visando evitar ou minimizar suas consequências potenciais indesejáveis (RITCHIE; BRINDLEY, 2009). Narasimhan e Talluri (2009) consideram a gestão de risco uma "atividade de gestão estratégica" (p.114). Kumar e Tewary (2007), nesta mesma linha, defendem que a forma como uma empresa gerencia seus riscos determina o seu sucesso ou fracasso.

A gestão de risco é uma estratégia que tem recebido uma atenção crescente na Embraer. A avaliação é realizada nos fornecedores diretos da empresa e envolve a análise de várias fontes potenciais de risco existentes no fornecedor e na sua base de fornecimento. Uma vez que um risco tenha sido identificado e avaliado como relevante, é definido um plano de ação visando reduzi-lo ou eliminá-lo. Segundo os entrevistados, o compartilhamento de fornecedores entre os diferentes clientes e os possíveis critérios de priorização adotados pelos fornecedores representam fontes potenciais de risco. Por conta disto, no processo de gestão de risco estas questões são analisadas. Isto permite que a empresa conheça estas fontes de risco e, se for o caso, defina planos específicos para tentar diminuir o seu grau de exposição. Mas, o problema é que outros membros da cadeia da empresa também podem enfrentar os mesmos riscos. Por exemplo: muitos itens importantes, como é o caso do motor e dos sistemas aeroestruturais, demandam volumes consideráveis de matérias-primas metálicas. Portanto, uma restrição na oferta de insumos importantes, originada em um ponto da cadeia, pode ser transmitida à Embraer sob a forma de falta de um sistema ou componente que não foi entregue pelo fornecedor pela indisponibilidade de seus insumos. Devido a isto, em seu processo de gestão de risco a Embraer não avalia apenas estes riscos da sua ótica, mas também analisa, em conjunto com os seus fornecedores da primeira camada, se eles também estão expostos a tais riscos. Neste contexto, o processo é integrado. A questão é que pontos de vulnerabilidade podem existir em partes mais a montante da cadeia da empresa. Passa a 
Análise da restrição da oferta de insumos básicos em períodos econômicos favoráveis da perspectiva de um fabricante de avião

depender dos seus fornecedores diretos, então, replicar esta análise junto às suas respectivas bases de fornecimento.

Nesta discussão sobre os riscos envolvendo as disputas entre os clientes pelos recursos limitados dos fornecedores, cabe levantar uma questão cuja importância tende a ficar cada vez mais evidente na indústria aeronáutica: considerando que a aplicação de materiais compósitos tem crescido significativamente, as disputas serão ampliadas a ponto de envolver este tipo de material? Harper (2008) responde: para este autor, os problemas que afetam atualmente o fornecimento de alumínio e titânio podem servir como "estudos de caso" visando evitar possíveis riscos de falta destes novos materiais no futuro.

Considerando tudo o que foi discutido neste item, o Quadro 1 resume os principais resultados desta pesquisa.

Quadro 1 - Principais resultados da pesquisa

\begin{tabular}{|c|c|}
\hline Problema e seu contexto & Estratégias para enfrentá-lo \\
\hline $\begin{array}{l}\text { - Características do mercado fornecedor, } \\
\text { concentração de fornecedores e compartilhamento } \\
\text { de fornecedores entre diferentes clientes } \\
\text { (empresas e indústrias) resultam na restrição da } \\
\text { oferta de insumos básicos em períodos } \\
\text { econômicos favoráveis; } \\
\text { Consequências: disputa, ainda que indireta, entre } \\
\text { os clientes por uma oferta restrita; flutuação da } \\
\text { oferta; aumentos de preço e lead-time de entrega; } \\
\text { Nestas circunstâncias pode haver priorização, por } \\
\text { parte dos fornecedores, de determinados clientes } \\
\text { (os mais importantes); } \\
\text { A restrição da oferta pode afetar diferentes } \\
\text { sistemas que compõem um avião, mas, } \\
\text { especificamente no caso de matérias-primas e } \\
\text { hardwares, as disputas se ampliam, pois } \\
\text { envolvem clientes que não pertencem à indústria } \\
\text { aeronáutica, além dos distribuidores. }\end{array}$ & $\begin{array}{l}\text { - Contrato de fornecimento formalizado com os } \\
\text { fornecedores (aspecto formal do relacionamento); } \\
\text { Aspecto informal do relacionamento: adoção de } \\
\text { práticas que visam melhorar o relacionamento } \\
\text { com os fornecedores e aumentar a confiança e o } \\
\text { comprometimento entre as empresas; } \\
\text { - Compartilhamento de informações (demanda } \\
\text { futura), devendo haver particular cuidado com a } \\
\text { acuracidade e a frequência de atualização das } \\
\text { informações; } \\
\text { Adoção de estoques de segurança, desde que a } \\
\text { implementação desta política seja planejada } \\
\text { antecipadamente com os fornecedores; } \\
\text { Gestão de risco em cadeias de suprimentos } \\
\text { (processo integrado com outros membros da } \\
\text { cadeia). }\end{array}$ \\
\hline
\end{tabular}

Fonte: elaborado pelo autor

\section{CONSIDERAÇÕES FINAIS}

Os fabricantes de avião compartilham fornecedores entre si e com outras indústrias. Em períodos econômicos favoráveis, a capacidade produtiva da base de fornecimento pode operar próximo do seu limite, gerando disputas (ainda que indiretas) entre os clientes pelos recursos limitados dos fornecedores. No caso de matérias-primas metálicas, os produtores tendem a tomar uma decisão de acréscimo da capacidade apenas quando têm segurança de que o maior nível de demanda é sustentável ou se manterá por um tempo suficientemente longo para cobrir seus investimentos. Por meio de um estudo de caso sobre a Embraer, foi 
possível identificar algumas estratégias que podem ser utilizadas para enfrentar as possíveis restrições da oferta de insumos básicos, nestas circunstâncias.

A pesquisa revelou que buscar a garantia do abastecimento por meio do compromisso formal (o contrato de fornecimento) é necessário, porém não suficiente. É essencial também, conjuntamente, buscar o compromisso informal, construído com base no bom relacionamento com os fornecedores. Este outro tipo de compromisso pode fazer a diferença nas situações em que o fornecedor é forçado a priorizar um ou poucos clientes, por não conseguir atender a todos. Portanto, planejar a gestão do relacionamento com os fornecedores, desde o nível operacional até o estratégico (ver CROXTON et al., 2001), e conhecer os atributos que favorecem um bom relacionamento devem fazer parte das responsabilidades da liderança da função compras. A gestão do relacionamento com os fornecedores está intrinsecamente associada a uma maior integração entre os membros de uma cadeia de suprimentos. Porém, este não foi o único resultado da pesquisa que aponta para esta direção. A pesquisa também mostrou que o compartilhamento de informações sobre a demanda futura é fundamental para que os fornecedores tenham mais segurança nas decisões sobre o aumento de suas taxas de produção e a necessidade de investimentos. Além disso, foi possível identificar que a gestão dos riscos relacionados às restrições de oferta de insumos básicos deve ser realizada por meio de um processo integrado, ou seja, executado conjuntamente pelos diferentes membros da cadeia (pelo menos, os mais importantes e influentes) de modo a garantir a sua replicação ao longo da cadeia, já que pontos de vulnerabilidade podem existir em diferentes camadas.

Neste contexto, nota-se que os resultados desta pesquisa apresentam estreita relação com a abordagem conhecida como Gestão da Cadeia de Suprimentos (GCS), cujo objetivo segundo Parra e Pires (2003, p.3) é "intensificar, somar e amplificar os benefícios de uma gestão integrada da cadeia de suprimentos". A implementação da GCS busca a "obtenção de uma cadeia produtiva mais eficiente" (PIRES, 1998, p.6; sobre a GCS, ver: LAMBERT; COOPER; PAGH, 1998; HALLDORSSON et al., 2007). De fato, o relacionamento entre os membros de uma cadeia, o compartilhamento de informações e a integração de processos estão associados àquilo que Fawcett e Magnan (2001, p.10) chamam de "blocos fundamentais de construção" da GCS, ou àquilo que Mentzer et al. (2001, p.15) chamam de "antecedentes" da GCS (que seriam os fatores que devem estar presentes nesta abordagem). Cabe também citar que a gestão de risco tem sido um tema recorrente na literatura sobre GCS (ver STOCK; BOYER; HARMON, 2010). 
Análise da restrição da oferta de insumos básicos em períodos econômicos favoráveis da perspectiva de um fabricante de avião

Portanto, os resultados desta pesquisa sugerem que a indústria aeronáutica representa um ambiente fértil para a aplicação (do ponto de vista prático) e a pesquisa (do ponto de vista acadêmico) da GCS. Além disso, por conta de seus objetivos e responsabilidades, a função compras pode ter um papel fundamental e decisivo na implementação e desenvolvimento desta abordagem no contexto dos fabricantes de avião, especialmente no que se refere às questões envolvendo a integração entre os membros da cadeia. É interessante notar que a importância da GCS no contexto da indústria aeronáutica já havia sido identificada por outros autores. Lam (2005) defende que a GCS será um dos meios pelos quais os fabricantes de avião alcançarão vantagens competitivas sustentáveis no futuro. Gostic (1998, p.79) utiliza o termo "proficiência em Gestão da Cadeia de Suprimentos", defendendo que as empresas precisam avançar na aplicação desta abordagem visando alcançar vantagem competitiva. Tiwari (2005), por sua vez, acredita que esta indústria oferece um ambiente interessante para o estudo de questões relacionadas à cadeia e como a GCS pode ser usada para manter a posição competitiva das empresas.

Vale destacar que esta pesquisa foi realizada em uma indústria que, embora entre as mais relevantes do mundo, costuma ser discutida com menos frequência na literatura em relação a outras tão ou até menos importantes (em termos econômicos) do que ela - devido à preferência dos pesquisadores ou por conta das dificuldades de acesso às informações das empresas pertencentes a este setor. Quem decide pesquisar os fabricantes de avião enfrenta a dificuldade de acesso às suas áreas e funcionários, já que estas empresas costumam ser bastante seletivas e cuidadosas ao divulgar ou fornecer informações sobre os seus processos internos. Esta estratégia ocorre porque a concorrência feroz nesta indústria poderia sofrer desequilíbrio caso uma empresa tivesse acesso a informações privilegiadas de outra. Embora compreensível esta estratégia acaba - pelo menos em parte - contribuindo para que os fabricantes de avião sejam menos estudados (e, portanto, menos conhecidos) do que outros tipos de empresas. Evidentemente, o pequeno número de fabricantes de avião existentes e a dispersão geográfica deles também são fatores determinantes.

Embora a opção pelo caso único, adotada nesta pesquisa, limite a sua abrangência em termos de resultados e conclusões, o autor acredita que ela não representa uma deficiência: os fabricantes de avião são tão interessantes, idiossincráticos e complexos que justificam pesquisas individuais. Assim, acredita-se que a Embraer pode, por si só, revelar questões importantes do ponto de vista científico. Considerando o objetivo e o tema desta pesquisa, é possível classificá-la como aquilo que Yin (2005), ao justificar um caso único, chama de 
"caso revelador": aquele que "ocorre quando o pesquisador tem a oportunidade de observar e analisar um fenômeno previamente inacessível à investigação científica" (p.63), "quando o caso serve a um propósito revelador" (p.67). No entanto, é fato que a validade externa desta pesquisa está restrita ao ambiente analisado pelo autor.

Os resultados e conclusões da pesquisa poderiam ter sido enriquecidos caso outras unidades de análise tivessem sido consideradas, além daquela adotada (a função compras de um fabricante de avião). Seria muito interessante, por exemplo, conhecer a perspectiva dos fornecedores da Embraer que também demandam os mesmos insumos básicos abordados nesta pesquisa e que, por isso, enfrentam o mesmo problema. Também seria igualmente interessante analisar o problema da perspectiva dos próprios produtores e fornecedores destes insumos. Além disso, a visão de informantes-chave ligados a outras áreas internas de um fabricante de avião a respeito do problema estudado poderia revelar questões não abordadas nesta pesquisa ou permitir uma compreensão mais completa daquelas que foram abordadas. As seguintes áreas seriam particularmente interessantes: produção (por ser o principal cliente da função compras), desenvolvimento de produto (por especificar os materiais usados na estrutura de produto e pelo conhecimento a respeito de novos materiais e tecnologias) e logística (por ser responsável pelos processos logísticos que envolvem os insumos básicos estudados).

Estas limitações da pesquisa servem como sugestões para estudos futuros que, sendo desenvolvidos, poderiam permitir a comparação entre casos e a extrapolação (ou não) dos resultados e conclusões desta pesquisa a outros ambientes. Espera-se que esta pesquisa e outras possam contribuir para a compreensão dos desafios e problemas enfrentados por uma função (compras) cuja importância é crescente em termos gerais, mas que as particularidades da indústria aeronáutica já a elevam a um patamar estratégico.

\section{REFERÊNCIAS}

ALVES FILHO, A. G. et al. Pressupostos da gestão da cadeia de suprimentos: evidências de estudos sobre a indústria automobilística. Gestão \& Produção, v.11, n.3, p.275-288, set./dez., 2004.

ARKHIPOVA, Y. A. Prospects for successfully exploiting the titanium mineral/raw-material base in Russia's Far East. Metallurgist, v.55, n.9-10, jan., 2012.

BARBIERI, M. Indústria aeronáutica. Campinas: Universidade Estadual de Campinas, Instituto de Economia, 2008. 21p. Relatório de acompanhamento setorial (número 1).

REAd | Porto Alegre - Edição 78 - N 2 - maio/agosto 2014 - p. 571-600 
Análise da restrição da oferta de insumos básicos em períodos econômicos favoráveis da perspectiva de um fabricante de avião

BASTOS, C. E. Atributos de parcerias de sucesso em cadeias de suprimentos: um estudo de caso na relação fabricante-fornecedor na indústria aeronáutica. 173p. Dissertação (Mestrado em Administração) - Universidade de São Paulo, 2006.

BEDAQUE JUNIOR, A. Alianças estratégicas e inovação de valor: estudo de caso dos jatos regionais 170/190 da Embraer. 151p. Dissertação (Mestrado em Administração) Pontifícia Universidade Católica, São Paulo, 2006.

BILCZO, T. et al. Aerospace supply chain dynamics. In: HARRISON, T. P.; LEE, H. L.; NEALE, J. J. (eds.). The practice of supply chain management: where theory and application converge. 2. ed. Springer, 2003. p.293-314.

BOURIKO, A. Quarterly comodity insights buletin. 2012. 4p. Disponível em: <www.kpmg.com>. Acesso em: 15/11/2012.

BUDIMAN, B. S. Optimal capacity adjustment for supply chain control. 124p. Tese (Doctor of Science) - Massachusetts Institute of Technology, 2004. Disponível em: <dspace.mit.edu>. Acesso em: 21/03/2010.

CARTER, P. L.; MONCZKA, R. M.; MOSCONI, T. Strategic performance measurement for purchasing and supply. 2005. 54p. CAPS: Center for Strategic Supply Research.

CHAGAS JUNIOR, M. F. A evolução dos modelos de gestão do processo de inovação tecnológica nas firmas: o caso da Embraer. 136p. Dissertação (Mestrado em Engenharia Mecânica e Aeronáutica) - Instituto Tecnológico de Aeronáutica, São José dos Campos, 2005.

CHUNXIANG, C.; BAOMIN, H.; LICHEN, Z.; SHUANGJIN, L. Titanium alloy production technology, market prospects and industry development. Materials and Design, v.32, p.1684-1691, 2011.

CLARKE, D. Contextual categorization of an aerospace OEM purchasing department. In: European Operations Management Association Conference, 17., 2010, Porto. Proceedings. p.1-10.

CROXTON, K. L. et al. The supply chain management processes. The International Journal of Logistics Management, v.12, n.2, p.13-36, 2001. 
CUCCHIELLA, F.; GASTALDI, M. Risk management in supply chain: a real option approach. Journal of Manufacturing Technology Management, v.17, n.6, p.700-720, 2006.

DORNA, M. A. S. et al. Rede de operações e integração vertical: risk-sharing agreements na cadeia produtiva aeronáutica brasileira. In: Encontro Nacional de Engenharia de Produção, 24., 2004, Florianópolis. Anais. p.3640-3647.

DWYER, F. R.; SCHURR, P. H.; OH, S. Developing buyer-seller relationships. Journal of Marketing, v.51, n.2, p.11-27, 1987.

EADS. EADS annual review 2009. 2010. 68p. Disponível em: 〈www.eads.com〉. Acesso em: 04/12/2010.

EISENHARDT, K. M. Building theories from case study research. The Academy of Management Review, v.14, n.4, p.532-550, 1989.

EMBRAER. Prospecto definitivo de distribuição pública secundária de ações ordinárias de emissão da Embraer. 2007. 680p. Disponível em: <www.embraer.com.br〉. Acesso em: 13/04/2009.

EMBRAER. Relatório anual 2010. 2011. 90p. Disponível em: <www.embraer.com.br>. Acesso em: 09/10/2011.

FAWCETT, S. E.; MAGNAN, G. M. Achieving world-class supply chain alignment: benefits, barriers and bridges. 2001. 159p. CAPS: Center for Strategic Supply Research.

FERNANDEZ, A. A. O desafio de crescer juntos. Bandeirante, v.35, n.718, p.13-15, dez., 2004.

FERREIRA, L. M. D. F. Compras na gestão da cadeia de abastecimento. In: CARVALHO, J. C. (ed.). Logística e gestão da cadeia de abastecimento. Edições Silabo, 2010. p.163-192.

FITZGERALD, K. R. Best practices in procurement. Ascet, v.4, p.84-87, 2002.

FORRESTER, J. W. Industrial dynamics: a major breakthrough for decision-makers. Harvard Business Review, v.36, n.4, p.37-66, 1958.

FORRESTER, J. W. Industrial dynamics. Cambridge: MIT Press, 1961. REAd | Porto Alegre - Edição 78 - N 2 - maio/agosto 2014 - p. 571-600 
Análise da restrição da oferta de insumos básicos em períodos econômicos favoráveis da perspectiva de um fabricante de avião

GOSTIC, W. J. Aerospace supply chain management. 84p. Dissertação (Master of Business Administration) - Massachusetts Institute of Technology, 1998. Disponível em: <dspace.mit.edu>. Acesso em: 21/03/2010.

GRAZIADIO, T. Estudo comparativo entre os fornecedores de componentes automotivos de plantas convencionais e modulares. 175p. Tese (Doutorado em Engenharia de Produção) - Escola Politécnica, Universidade de São Paulo, São Paulo, 2004.

GUERRA, J. H. L. O modelo de integração de sistemas da indústria aeronáutica: fatores motivadores. Gestão \& Produção, São Carlos, v.18, n.2, p.251-264, 2011.

GUERRA, J. H. L. Proposta de um protocolo para o estudo de caso em pesquisas qualitativas. In: Encontro Nacional de Engenharia de Produção, 30., 2010, São Carlos. Anais. p.1-13.

HALLDORSSON, A. et al. Complementary theories to supply chain management. Supply Chain Management: an International Journal, v.12, n.4, p.284-296, 2007.

HARPER, B. C. Root cause analysis and mitigation paths for persistent inventory shortages to an assembly area. 90p. Dissertação (Master of Science) - Massachusetts Institute of Technology, 2008. Disponível em: <dspace.mit.edu>. Acesso em: 12/08/2010.

HAYES, P. B. Russia's raw materials business on the rise. Aerospace America, International Beat, p.4-6, jan., 2008.

HENRIQUES, V. A. R. Titanium production for aerospace applications. Journal of Aerospace Technology and Management, v.1, n.1, p.7-17, 2009.

ILUKA. Mineral sands products: attributes and applications. 2011. 10p. Disponível em: <www.iluka.com>. Acesso em: 15/11/2012.

JOHNSON, P. F.; LEENDERS, M. R.; FLYNN, A. E. Purchasing and supply management. In:__. Purchasing and supply management. 14. ed. McGraw-Hill/Irwin, 2010. p.1-25.

JOHNSSON, J.; GREISING, D. Behind Boeing's 787 delays. 2007. Disponível em: <archives.chicagotribune.com>. Acesso em: 20/05/2010. 
JOYCE, W. B. Accounting, purchasing and supply chain management. Supply Chain Management: an International Journal, v.11, n.3, p.202-207, 2006.

KARY, J. R. Advanced aerospace procurement models with sensitivity analysis and optimized demand allocation. 80p. Dissertação (Master of Science) - Massachusetts Institute of Technology, 2006. Disponível em: <dspace.mit.edu>. Acesso em: 21/03/2010.

KHAN, O.; BURNES, B. Risk and supply chain management: creating a research agenda. The International Journal of Logistics Management, v.18, n.2, p.197-216, 2007.

KING, J. F. Trends in the aluminium industry: implications for metal supply. Metal-Pages Conference: Metals for the aerospace industry, 2008, Barcelona. Disponível em:

<cdn.steelonthenet.com/pdf/aluminium_industry_trends.pdf>. Acesso em: 11/12/2012.

KOUVELIS, P.; CHAMBERS, C.; WANG, H. Supply chain management research and production and operations management: review, trends, and opportunities. Production and Operations Management, v.15, n.3, p.449-469, 2006.

KUMAR, S.; TEWARY, A. K. Creating supply chain flexibility in the flattening world. SETLabs Briefings, v.5, n.3, p.1-12, 2007.

LAM, Y. Y. R. Designing and implementing a new supply chain paradigm for airplane development. 60p. Dissertação (Master of Science) - Massachusetts Institute of Technology, 2005. Disponível em: <dspace.mit.edu>. Acesso em: 21/03/2010.

LAMBERT, D. M.; COOPER, M. C.; PAGH, J. D. Supply chain management: implementation issues and research opportunities. The International Journal of Logistics Management, v.9, n.2, p.1-19, 1998.

LEE, H. L. Creating value through supply chain integration. Supply Chain Management Review, sep./oct., 2000. Disponível em: <www.scmr.com/article/CA151843.html>. Acesso em: 05/05/2009.

LIMA, J. C. C. O. et al. A cadeia aeronáutica brasileira e o desafio da inovação. BNDES Setorial, n.21, p.31-55, mar., 2005.

MARTINEZ, M. R. E. A globalização da indústria aeronáutica: o caso da Embraer. 340p. Tese (Doutorado em Relações Internacionais) - Instituto de Relações Internacionais, Universidade de Brasília, Brasília, 2007. 
Análise da restrição da oferta de insumos básicos em períodos econômicos favoráveis da perspectiva de um fabricante de avião

MELOUK, S. H. et al. Simulation optimization-based decision support tool for steel manufacturing. International Journal of Production Economics, v.141, n.1, p.269-276, 2012.

MENTZER, J. T. et al. What is supply chain management? In: Mentzer, J. T. (ed.). Supply chain management. Sage, 2001. p.1-25.

MIGUEL, P. A. C. Estudo de caso na engenharia de produção: estruturação e recomendações para sua condução. Produção, v.17, n.1, p.216-229, jan./abr., 2007.

MORON, M. A. M. Concepção, desenvolvimento e validação de instrumentos de coleta de dados para estudar a percepção do processo decisório e as diferenças culturais. 239p. Dissertação (Mestrado em Administração de Empresas) - Universidade Federal do Rio Grande do Sul, 1998.

NADARAJAN, S.; CHANDREN, S. Review on causes of raw materials shortages on electronic base manufacturing built to order perspective. European Journal of Scientific Research, v.66, n.2, p.219-224, 2011.

NARASIMHAN, R.; TALLURI, S. Editorial: perspectives on risk management in supply chains. Journal of Operations Management, v.27, n.2, p.114-118, 2009.

NIOSI, J.; ZHEGU, M. Aerospace clusters: local or global knowledge spillovers? Industry and Innovation, v.12, n.1, p.1-25, mar., 2005.

OECD. Aluminium. In: OECD Global Forum on Environment: Sustainable materials management, 2010, Mechelen. Working Document. Materials Case Study 2. 66p. (Work in progress)

OLSON, D. L.; WU, D. D. A review of enterprise risk management in supply chain. Kybernetes, v.39, n.5, p.694-706, 2010.

PARRA, P. H.; PIRES, S. R. I. Análise da gestão da cadeia de suprimentos na indústria de computadores. Gestão \& Produção, v.10, n.1, p.1-15, abr., 2003.

PIERREVAL, H.; BRUNIAUX, R.; CAUX, C. A continuous simulation approach for supply chains in the automotive industry. Simulation Modelling Practice and Theory, v.15, p.185$198,2007$. 
PIMPÃO, M.; FERREIRA, L. M. D. F. Supply chain risks and mitigation strategies: an exploratory study in the Portuguese industrial sector. In: European Operations Management Association Conference, 17., 2010, Porto. Proceedings. p.1-9.

PIRES, S. R. I. Gestão da cadeia de suprimentos e o modelo de consórcio modular. Revista de Administração, v.33, n.3, p.5-15, jul./set., 1998.

POWER, D. Supply chain management integration and implementation: a literature review. Supply Chain Management: an International Journal, v.10, n.4, p.252-263, 2005.

PRADO, M. I. Eletrônicos: do lixo ao lucro - a escassez de matéria prima para a contínua comercialização de produtos eletrônicos e o peso para a reciclagem pós-consumo.

Universitas Gestão e TI, v.2, n.1, p.27-33, 2012.

PRAHALAD, C. K.; HAMEL, G. The core competence of the corporation. Harvard Business Review, v.68, n.3, p.79-91, 1990.

RANDON, V.; NETO, V. P. Ligas avançadas utilizadas no desenvolvimento de peças para a indústria empregam processos sofisticados. Revista metalurgia e materiais, Caderno Técnico, p.591-593, 2005.

RITCHIE, B.; BRINDLEY, C. Effective management of supply chains: risks and performance. In: Wu, T.; Blackhurst, J. (eds.). Managing supply chain risk and vulnerability. Springer, 2009. p.9-40.

SANTIAGO, M. P. Project finance: análise comparativa de financiamento de projetos. 165p. Dissertação (Mestrado em Engenharia de Produção) - Universidade Federal de Minas Gerais, 2002.

SEONG, D.; SUH, M. S. An integrated modeling approach for raw material management in a steel mill. Production Planning and Control, v.23, n.12, p.922-934, 2012.

STEVENSON, M.; SPRING, M. Flexibility from a supply chain perspective: definition and review. International Journal of Operations and Production Management, v.27, n.7, p.685-713, 2007.

STOCK, J. R.; BOYER, S. L.; HARMON, T. Research opportunities in supply chain management. Journal of the Academy of Marketing Science, v.38, n.1, p.32-41, 2010. 
Análise da restrição da oferta de insumos básicos em períodos econômicos favoráveis da perspectiva de um fabricante de avião

SUCUPIRA, C. Metodologia para implementação da gestão da cadeia de suprimentos. 21p. 2007.

TEXIER, F. Airbus fasteners' supply chain optimization: how to stock, prepare and distribute in the most efficient way? 117p. Dissertação (Master of Science) - Lund Institute of Technology, 2008. Disponível em: <www.tlog.lth.se>. Acesso em: 04/02/2011.

THE ECONOMIST. Barrelling along: Boeing has hit some snags with the 787, but still has the edge over Airbus's A350. 2007. Disponível em: <www.economist.com〉. Acesso em: 27/01/2010.

TIMET (Titanium Metals Corporation). 2011 Annual Report. 2011. 96p. Disponível em: <www.timet.com>. Acesso em: 16/11/2012.

TIWARI, M. An exploration of supply chain management practices in the aerospace industry and in Rolls-Royce. 96p. Dissertação (Master of Engineering) - Massachusetts Institute of Technology, 2005. Disponível em: <dspace.mit.edu>. Acesso em: 21/03/2010.

VACHA JUNIOR, R. L. Strategic raw material inventory optimization. 85p. Dissertação (Master of Science) - Massachusetts Institute of Technology, 2007. Disponível em: <dspace.mit.edu>. Acesso em: 21/03/2010.

VAN HOECKE, M. P.; LEROY, M. J. F. Metals: supply shortage of strategical raw materials. Actualite Chimique, n.358, p.24-29, dec., 2011.

VAN WEELE, A. J. Purchasing and supply chain management. 5. ed. Londres: Cengage Learning, 2010.

WATERS, D. Supply chain risk management: vulnerability and resilience in logistics. Kogan Page, 2007. 264p.

YIN, R. K. Estudo de caso: planejamento e métodos. 3. ed. Porto Alegre: Bookman, 2005. $212 p$. 